\title{
Analysis of rainfall variation over northern parts of Nigeria
}

\author{
Mustapha Baba-Aji Mamman*, Ahmad A. Bello, Ahmad A. Usman \\ Nigerian Meteorological Agency, National Weather Forecasting and Climate Research Center, Abuja 900421, Nigeria
}

Corresponding Author Email: massa165@gmail.com

http//doi.org/10.18280/eesrj.050304

Received: 4 July 2018

Accepted: 29 August 2018

\section{Keywords:}

rainfall, Northern Nigeria, skewness, kurtosis, coefficient of variation

\begin{abstract}
This study investigates rainfall variation in some parts of northern Nigeria. This was done by assessing the variations in rainfall characteristics in the study area; to identify areas/stations with highest/lowest mean annual rainfall amount and finally predict the values for the periods 2012 to 2030. Monthly rainfall amount data of fourteen synoptic stations in some parts of Northern Nigeria used in this study for the period of forty-two years (19712012) was obtained from the Nigerian Meteorological Agency. Statistical measures (mean, median, maximum, minimum, standard deviation, variance, skewness, kurtosis and coefficient of variation), time series and forecast the year 2030. The analysis of rainfall variations from the study area shows that Jos recorded the highest mean annual rainfall amount of $1263.2 \mathrm{~mm}$ and Nguru recorded the lowest amount of $470.2 \mathrm{~mm}$ over the years, which also has the minimum rainfall variability with $12 \%$ coefficient of variation. The year 2001 recorded the highest mean annual rainfall total of $14991.3 \mathrm{~mm}$, while 1983 recorded the lowest amount $(645.7 \mathrm{~mm})$. Kano has the highest coefficient of variation value of $38 \%$ during the study period. Thus, rainfall has been on the increase within the study periods.
\end{abstract}

\section{INTRODUCTION}

Rainfall stands out as perhaps the single, most unique element of all the climatic elements such that it's total amount, intensity, duration, variability, reliability and its spatial and temporal distribution influence phenomenon especially in the tropical region where prevailing economic activity is simply agro-based [1-2].

Recently, in Africa and Nigeria in particular, the emphasis of many scholars in the study of tropical climatology has been the consideration of rainfall characteristics, such as rainfall amount, duration and intensity. Rainfall is the meteorological phenomenon that has the greatest impact on human activities and the most important environmental factor limiting the development of the semiarid regions [3]. Understanding rainfall variability is essential to optimally manage the scarce water resources that are under continuous stress due to the increasing water demands, increase in population, and the economic development [4]

In Nigeria, the dominant feature of rainfall is its seasonal character. The large energy content of rainfall system is its variability from year to year which is mainly attributed to the fluctuation in the movement of the two different dominant air masses, the Inter Tropical Discontinuity [5-6]. Despite the recent advances made in science and technology, farmers and their crops are still left at the mercy of rainfall especially in Sub-Saharan Africa, where the Northern region of Nigeria lies. Hence water supply for agricultural practices is highly dependent on precipitation. Moreover in areas where the climate is greatly influenced by drought and desertification, the condition of precipitation in relation to yield, the rate of evapo-transpiration and soil moisture content may help promote or hinder crop production. This is subject to availability of moisture at the evaporating surface and the ability of the atmosphere to vaporize the water.

The variability of rainfall and the pattern of extreme high or low precipitation are very important for agriculture as well as the economy of the state. It is well established that the rainfall is changing on both the global and the regional scales due to global warming [7-8].

The knowledge of climate variability over the period of instrumental records and beyond on different temporal and spatial scale is important to understand the nature of different climate systems and their impact on the environment and society [9].

Earlier studies in this region indicate declining annual rainfall totals creating scarcity of water for agricultural production and needs for more effective water resources development [10-11]. Most of these studies were based on records terminating in the late 1980s and the early 1990s.

Adefolalu [12] studied the rainfall trends for periods of 1911-1980 over 28 meteorological stations in Nigeria with 40 years moving average showing appearance of declining rainfall. Eludoyin et al. [13] studied monthly rainfall distribution in Nigeria between 1985-1994 and 1995-2004 and noticed some fluctuations in most months within the decades.

\section{STUDY AREA}

The study areas lies between latitudes $9^{\circ} \mathrm{N}$ to $14^{\circ} \mathrm{N}$ and longitudes $3^{\circ} \mathrm{E}$ to $14^{\circ} \mathrm{E}$. The synoptic stations used in the study are shown in Figure 1. 


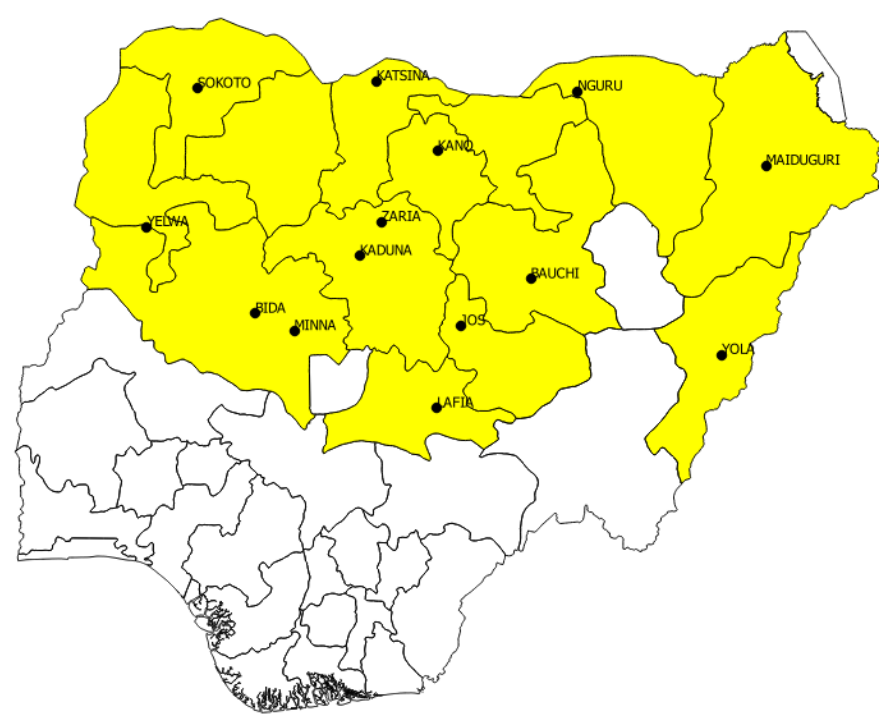

Figure 1. Map of Nigeria showing study area

\section{MATERIALS AND METHODS}

\subsection{Data}

The data used in this study include monthly rainfall $(\mathrm{mm})$ for fourteen synoptic stations in northern parts of Nigeria from the Nigerian Meteorological Agency for the period of 1971 to 2012. Interpolation and averaging for missing data were done for Bauchi, Bida, Minna, Yola, Zaria and Jos.

\subsection{Method}

Microsoft excel statistical software package and Statistical Package for Social Sciences (SPSS) were used for the analysis. The data were subjected to statistical analysis using measures of central tendency such as mean, mean deviation and median; measures of dispersion such as range, variance and standard deviation as well as a measure of relationship (coefficient of variance).

Mean $=\frac{\sum_{i=1}^{n} X i}{n}$
Variance $=\frac{\sum_{(x-x)}{ }^{2}}{n-1}$

Coefficient of Variation $(\mathrm{CV})=\frac{S D}{\bar{X}} \times 100$

where: SD is standard deviation $=\sqrt{\frac{\sum_{(x-x)^{2}}}{n-1}}$

\section{RESULTS AND DISCUSSION}

\subsection{Statistics of rainfall summaries in the study area by stations}

Table 1 shows the result of the statistical analysis for rainfall summaries by stations. The highest amount of mean annual rainfall in the study area from 1971-2012 was observed in Jos with total sum of $1263.2 \mathrm{~mm}$, followed by Minna (1206.5mm) and Kaduna with $1198.1 \mathrm{~mm}$ respectively. While, the least amount was recorded at Nguru with the sum of $419.0 \mathrm{~mm}$, followed by Katsina with $548.1 \mathrm{~mm}$ and Maiduguri with the sum of $569.6 \mathrm{~mm}$ respectively.

Table 1. Statistics summaries of mean annual rainfall by station from 1971-2012

\begin{tabular}{|c|c|c|c|c|c|c|c|c|c|c|c|c|}
\hline $\begin{array}{l}\text { SYNOPTIC } \\
\text { STATION }\end{array}$ & $\begin{array}{c}\text { NUMBER } \\
\text { OF YEARS } \\
\text { (1971-2012) }\end{array}$ & SUM & MEAN & MEDIAN & MINIMUM & MAXIMUM & RANGE & VARIANCE & SD & KURTOSIS & SKEWNESS & C.V\% \\
\hline BAUCHI & 42 & 41441.4 & 1036.0 & 989.8 & 725.6 & 1619.6 & 894.0 & 41571.5 & 203.9 & 0.9 & 0.9 & 20 \\
\hline BIDA & 42 & 46767.0 & 1113.5 & 1144.1 & 213.1 & 1407.7 & 1194.6 & 40493.5 & 201.2 & 8.8 & -2.2 & 18 \\
\hline JOS & 42 & 53052.9 & 1263.2 & 1246.6 & 814.7 & 1646.2 & 831.5 & 23948.4 & 154.8 & 1.8 & -0.3 & 12 \\
\hline KADUNA & 42 & 50319.9 & 1198.1 & 1224.4 & 827.9 & 1484.9 & 657.0 & 28948.4 & 170.1 & -0.4 & -0.3 & 14 \\
\hline KANO & 42 & 39907.5 & 950.2 & 919.7 & 416.1 & 1872.0 & 1455.9 & 131691.5 & 362.9 & 0 & 0.7 & 38 \\
\hline KATSINA & 42 & 23020.5 & 548.1 & 542.8 & 262.0 & 955.7 & 693.7 & 25139.6 & 158.6 & -0.4 & 0.3 & 30 \\
\hline MAIDUGURI & 42 & 22785.2 & 569.6 & 587.8 & 263.5 & 897.1 & 633.6 & 21839.1 & 147.8 & -0.6 & 0 & 26 \\
\hline MINNA & 42 & 50672.2 & 1206.5 & 1215.3 & 823.4 & 1582.9 & 759.5 & 28180.4 & 167.9 & 0.4 & -0.3 & 14 \\
\hline NGURU & 42 & 17597.3 & 419.0 & 415.2 & 226.7 & 696.9 & 470.2 & 15437.7 & 124.3 & -0.4 & 0.4 & 30 \\
\hline POTISKUM & 42 & 24435.0 & 643.0 & 648.5 & 372.0 & 966.1 & 594.1 & 22397.0 & 149.7 & -0.4 & -0.1 & 23 \\
\hline Sокото & 42 & 25976.1 & 633.6 & 626.7 & 373.2 & 1146.7 & 773.5 & 21511.2 & 146.7 & 2.4 & 0.9 & 23 \\
\hline YELWA & 42 & 41751.3 & 994.1 & 978.4 & 584.0 & 1566.2 & 982.2 & 32220.4 & 179.5 & 3.3 & 1.1 & 18 \\
\hline YOLA & 42 & 35694.8 & 870.6 & 908.8 & 468.5 & 1121.7 & 653.2 & 23884.2 & 154.6 & 0.6 & -0.9 & 18 \\
\hline ZARIA & 42 & 43046.9 & 1024.9 & 992.2 & 685.6 & 1409.3 & 723.7 & 26896.8 & 164.0 & -0.3 & 0.2 & 16 \\
\hline
\end{tabular}


Kano recorded the highest maximum annual rainfall total with the sum of $1872.0 \mathrm{~mm}$, while Bida recorded the lowest minimum annual rainfall total with the sum of $213.1 \mathrm{~mm}$. Nevertheless, Kano also had the highest rainfall range of $1455.9 \mathrm{~mm}$ and the least was observed at Nguru (470.2mm).

The skewness showed negative values in Kaduna, Bida, Yola and Jos (i.e. the stations had the tendency of below average rainfall distribution), while other stations had positive skewness (i.e. the tendency of having above average rainfall distribution).

The coefficient of variation shows that $38 \%$ variation occurred in Kano within the study period. This makes Kano station with highest rainfall variability, followed by Katsina and Nguru with values of $29 \%$ and $30 \%$ each. While Jos, Katsina and Minna recorded the least stations with values of $12 \%$ and $14 \%$ each respectively.

\subsection{Annual rainfall summaries}

Table 2 shows the statistical summaries of mean annual rainfall from 1971-2012. The year 2001 recorded the highest mean annual rainfall total of $14991.3 \mathrm{~mm}$, followed by 2003 (14437.7mm), $1978(14235.8 \mathrm{~mm})$ and 1999 with the total sum of $14330.0 \mathrm{~mm}$. While, the least mean annual rainfall total was recorded in 1983 (9040.3mm) and 1987 (9893.6mm).

Table 2. Statistics of mean annual rainfall summaries in the study area (1971-2012)

\begin{tabular}{|c|c|c|c|c|c|c|c|c|c|c|c|c|}
\hline \multirow[t]{2}{*}{ YEAR } & \multicolumn{12}{|c|}{ STATISTICS } \\
\hline & $\begin{array}{l}\text { NO. OF } \\
\text { STATION }\end{array}$ & SUM & AVERAGE & MEDIAN & MINIMUM & MAXIMUM & RANGE & SD & VARIANCE & KURTOSIS & SKEWNESS & C.V \% \\
\hline 1971 & 14 & 11895.0 & 849.6 & 852.7 & 328.3 & 1431.8 & 1103.5 & 345.4 & 119285.1 & -1.2 & 0.1 & 41 \\
\hline 1972 & 14 & 11488.9 & 820.6 & 846.8 & 247.6 & 1368.3 & 1120.7 & 339.3 & 115157.9 & -0.7 & 0.1 & 41 \\
\hline 1973 & 14 & 10270.1 & 733.6 & 786.4 & 258.9 & 1360.7 & 1101.8 & 343.6 & 118091.7 & -1.0 & 0.3 & 47 \\
\hline 1974 & 14 & 13231.8 & 945.1 & 975.5 & 472.2 & 1441.2 & 969.0 & 315.0 & 99203.9 & -1.5 & 0.0 & 33 \\
\hline 1975 & 14 & 12650.8 & 903.6 & 819.6 & 544.1 & 1393.6 & 849.5 & 331.7 & 110046.9 & -1.4 & 0.5 & 37 \\
\hline 1976 & 14 & 13108.4 & 936.3 & 939.4 & 430.9 & 1446.3 & 1015.4 & 327.7 & 107386.4 & -1.3 & 0.0 & 35 \\
\hline 1977 & 14 & 11829.3 & 845.0 & 841.5 & 372.0 & 1354.4 & 982.4 & 262.1 & 68708.6 & 0.1 & 0.1 & 31 \\
\hline 1978 & 14 & 14235.2 & 1016.8 & 962.4 & 496.7 & 1582.9 & 1086.2 & 382.5 & 146327.7 & -1.5 & 0.1 & 38 \\
\hline 1979 & 14 & 13083.8 & 934.6 & 894.9 & 587.8 & 1476.0 & 888.2 & 274.9 & 75542.7 & -0.6 & 0.6 & 29 \\
\hline 1980 & 14 & 12502.1 & 893.0 & 896.9 & 339.6 & 1287.2 & 947.6 & 280.1 & 78449.0 & -0.5 & -0.3 & 31 \\
\hline 1981 & 14 & 12045.4 & 860.4 & 930.3 & 428.9 & 1272.4 & 843.5 & 303.7 & 92252.1 & -1.6 & -0.1 & 35 \\
\hline 1982 & 14 & 11442.9 & 817.4 & 876.9 & 354.0 & 1330.4 & 976.4 & 345.2 & 119165.7 & -1.4 & 0.1 & 42 \\
\hline 1983 & 14 & 9040.3 & 645.7 & 652.1 & 226.7 & 1086.2 & 859.5 & 247.9 & 61444.7 & -0.5 & -0.1 & 38 \\
\hline 1984 & 14 & 10594.1 & 756.7 & 823.0 & 331.3 & 1345.0 & 1013.7 & 346.9 & 120349.3 & -1.4 & 0.2 & 46 \\
\hline 1985 & 14 & 11112.9 & 793.8 & 759.2 & 399.2 & 1223.1 & 823.9 & 325.8 & 106151.0 & -1.8 & 0.1 & 41 \\
\hline 1986 & 14 & 11534.1 & 823.9 & 832.4 & 240.5 & 1229.9 & 989.4 & 297.9 & 88756.7 & -0.6 & -0.4 & 36 \\
\hline 1987 & 14 & 9893.6 & 706.7 & 722.8 & 251.3 & 1289.1 & 1037.8 & 339.1 & 114979.6 & -1.1 & 0.4 & 48 \\
\hline 1988 & 14 & 12991.5 & 928.0 & 1014.2 & 320.6 & 1237.7 & 917.1 & 291.3 & 84842.2 & -0.1 & -1.0 & 31 \\
\hline 1989 & 14 & 11356.1 & 811.2 & 785.4 & 338.6 & 1232.0 & 893.4 & 266.8 & 71206.7 & -0.8 & 0.1 & 33 \\
\hline 1990 & 14 & 10713.8 & 765.3 & 810.3 & 242.1 & 1230.9 & 988.8 & 302.7 & 91603.6 & -1.0 & -0.1 & 40 \\
\hline 1991 & 14 & 12768.7 & 912.1 & 914.0 & 235.5 & 1411.4 & 1175.9 & 382.7 & 146454.5 & -1.1 & -0.4 & 42 \\
\hline 1992 & 14 & 12075.2 & 862.5 & 961.8 & 333.1 & 1241.9 & 908.8 & 315.0 & 99240.8 & -1.1 & -0.6 & 37 \\
\hline 1993 & 14 & 12029.9 & 859.3 & 966.2 & 262.0 & 1250.7 & 988.7 & 329.6 & 108668.4 & -0.9 & -0.6 & 38 \\
\hline 1994 & 14 & 13214.0 & 943.9 & 906.3 & 453.1 & 1537.3 & 1084.2 & 326.1 & 106323.6 & -0.6 & 0.2 & 35 \\
\hline 1995 & 14 & 11658.4 & 832.7 & 888.1 & 317.7 & 1279.3 & 961.6 & 308.9 & 95448.8 & -1.2 & -0.2 & 37 \\
\hline 1996 & 14 & 12772.1 & 912.3 & 989.4 & 268.8 & 1382.0 & 1113.2 & 334.6 & 111969.0 & -0.7 & -0.5 & 37 \\
\hline 1997 & 14 & 13363.0 & 954.5 & 1021.2 & 493.3 & 1329.3 & 836.0 & 312.1 & 97395.8 & -1.6 & -0.3 & 33 \\
\hline 1998 & 14 & 14153.1 & 1010.9 & 1067.1 & 431.6 & 1872.0 & 1440.4 & 368.0 & 135409.8 & 1.3 & 0.5 & 36 \\
\hline 1999 & 14 & 14330.0 & 1023.6 & 1069.5 & 310.9 & 1566.2 & 1255.3 & 374.5 & 140213.5 & -0.6 & -0.5 & 37 \\
\hline 2000 & 14 & 13033.2 & 930.9 & 1028.5 & 353.8 & 1274.5 & 920.7 & 297.9 & 88726.0 & -0.9 & -0.6 & 32 \\
\hline 2001 & 14 & 14991.3 & 1070.8 & 1193.0 & 466.0 & 1789.4 & 1323.4 & 350.0 & 122482.0 & -0.1 & 0.1 & 33 \\
\hline 2002 & 14 & 12663.7 & 904.6 & 921.6 & 441.6 & 1582.7 & 1141.1 & 316.8 & 100391.4 & 0.3 & 0.4 & 35 \\
\hline 2003 & 14 & 14437.7 & 1031.3 & 930.1 & 653.3 & 1468.3 & 815.0 & 286.1 & 81848.4 & -1.4 & 0.3 & 28 \\
\hline 2004 & 14 & 13546.9 & 967.6 & 1055.1 & 543.0 & 1379.4 & 836.4 & 284.1 & 80735.6 & -1.5 & -0.3 & 29 \\
\hline 2005 & 14 & 13135.7 & 938.3 & 947.2 & 519.1 & 1376.3 & 857.2 & 248.4 & 61708.0 & -0.7 & 0.0 & 26 \\
\hline 2006 & 14 & 13091.1 & 935.1 & 964.7 & 409.5 & 1524.0 & 1114.5 & 308.9 & 95445.1 & -0.3 & 0.1 & 33 \\
\hline 2007 & 14 & 11915.8 & 851.1 & 814.6 & 213.1 & 1409.9 & 1196.8 & 324.8 & 105486.0 & -0.3 & -0.1 & 38 \\
\hline 2008 & 14 & 11467.8 & 819.1 & 840.5 & 338.9 & 1271.3 & 932.4 & 315.8 & 99718.9 & -1.4 & 0.0 & 39 \\
\hline 2009 & 12 & 12421.9 & 955.5 & 992.2 & 366.5 & 1531.3 & 1164.8 & 398.6 & 158891.5 & -1.5 & -0.2 & 42 \\
\hline 2010 & 12 & 13558.3 & 1042.9 & 1098.1 & 466.5 & 1619.6 & 1153.1 & 285.1 & 81268.5 & 1.1 & -0.1 & 27 \\
\hline 2011 & 11 & 10166.6 & 924.2 & 1020.5 & 398.9 & 1646.2 & 1247.3 & 378.5 & 143264.7 & -0.4 & 0.2 & 41 \\
\hline 2012 & 9 & 10653.5 & 1183.7 & 1231.0 & 696.9 & 1680.0 & 983.1 & 354.0 & 125351.2 & -1.5 & -0.2 & 30 \\
\hline
\end{tabular}

The minimum amount of rainfall was recorded in 2007 with a value of $213.1 \mathrm{~mm}$ followed by 1991 (235.5mm), 1990 $(242.1 \mathrm{~mm})$ and $1993(262.0 \mathrm{~mm})$ respectively. Thus, the highest amounts of maximum rainfall were recorded in 1998 with a value of $1872.0 \mathrm{~mm}$ followed by $2001(1789.4 \mathrm{~mm})$,
2012 (1680.0mm) and 2010 (1619.6mm).

The distribution of the data is positively skewed in 1971, 1972, 1973, 1974, 1975, 1977, 1978, 1979, 1982, 1984, 1985, 1987, 1989, 1994, 1998, 2001, 2002, 2003, 2005, 2006, 2008 and 2011 (i.e. the tendency of having above average rainfall 
distribution). Other years not mentioned were negatively skewed. The kurtosis showed a negative value in 1977, 1988, 2002 and 2010 (i.e. flatter than normal peak distributions). While the other years had negative kurtosis (i.e. peak flattest than the average) values during the year of consideration. The year 1987 has the highest coefficient of variation value of $48 \%$ followed by 1973 (47\%) and 1984 (46\%), while the least was recorded in 2005 with a value of $26 \%$ followed by the year $2010(27 \%)$ and $2003(28 \%)$ as shown in table 2.

\subsection{Rainfall distribution trend}

\subsubsection{Mean annual rainfall distribution}

The mean annual rainfall distribution from the study area ranges from $420 \mathrm{~mm}$ to $1263 \mathrm{~mm}$ over the entire 42 years of study. Generally, there were upward and downward shifts during the study period.

An upward trends of mean annual rainfall are significant in Bauchi as shown in figure 2, Katsina (figure 3) Maiduguri (figure 4), Nguru (figure 5) and Yelwa (figure 6) respectively. However, downward rainfall trends were also noticeable at Kaduna and Yola stations (figure $7 \& 8$ ). A downward trend was noticed in the mean annual rainfall in all stations from 1983-1984, it was later rise up steady till 2008 as shown in figure 9.

The time series straight line equation obtained $(y=3.8229 x+811.83)$. This indicates that a continuous rise from 1971 to 2012 . This was an evidence that rainfall was improving in the study area as shown in figure 9.

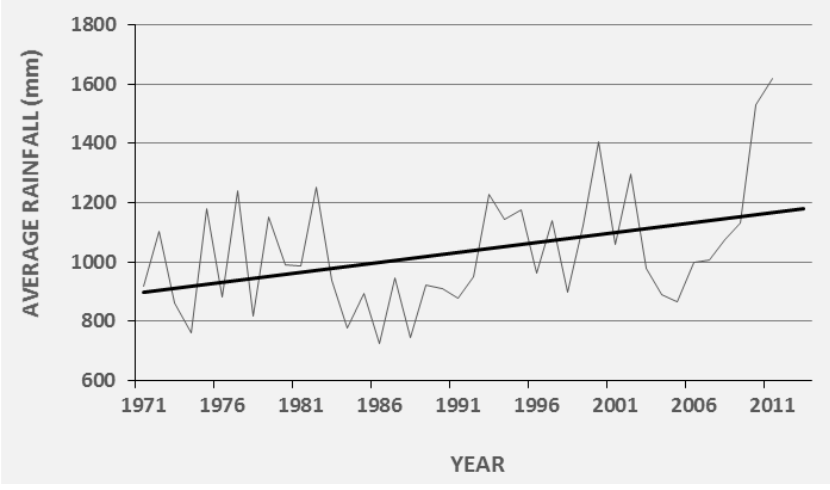

Figure 2. Mean annual rainfall total in Bauchi from 19712012

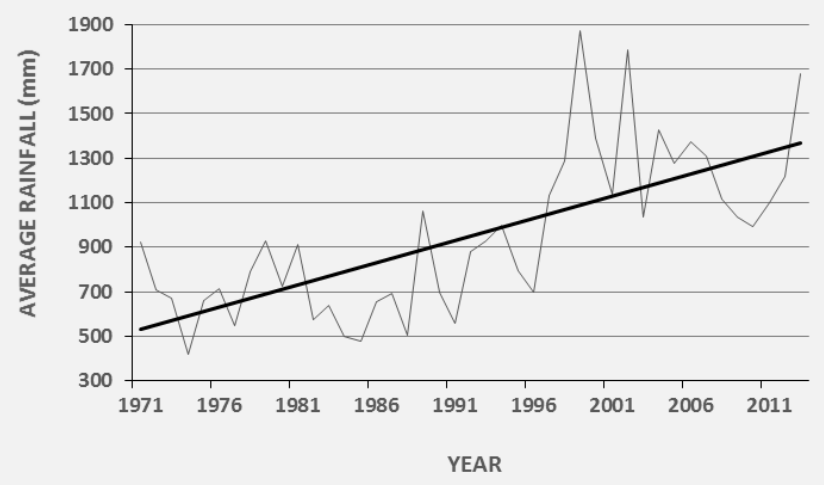

Figure 3. Mean annual rainfall total in Katsina from 19712012

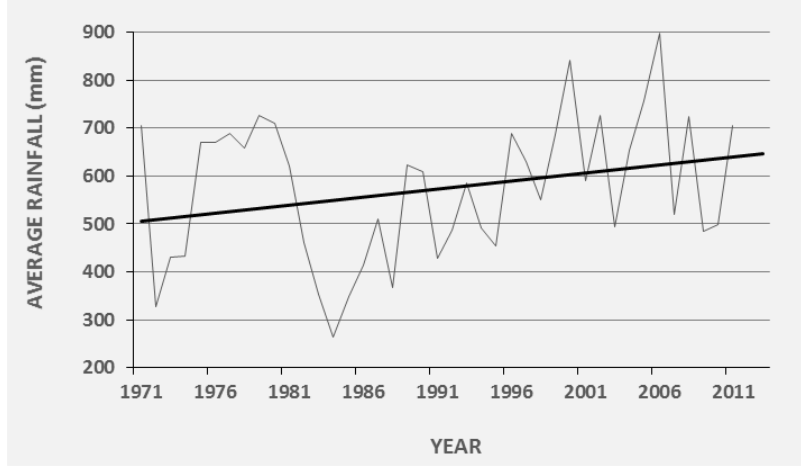

Figure 4. Mean annual rainfall total in Maiduguri from 19712012

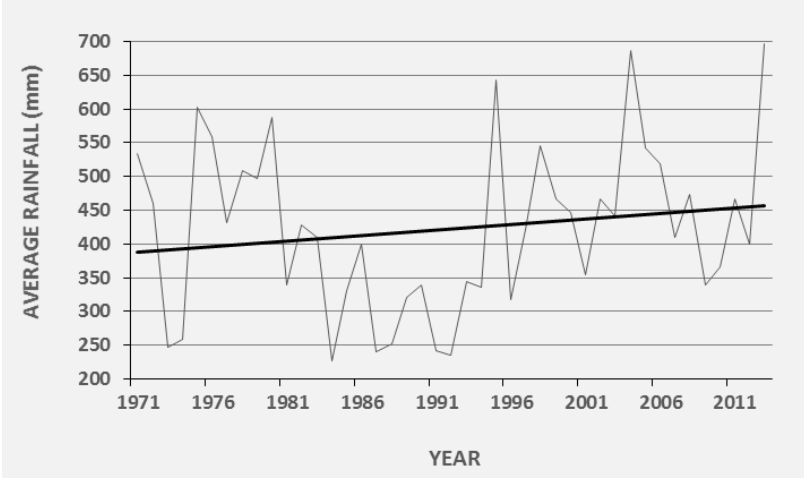

Figure 5. Mean annual rainfall total in Nguru from 19712012

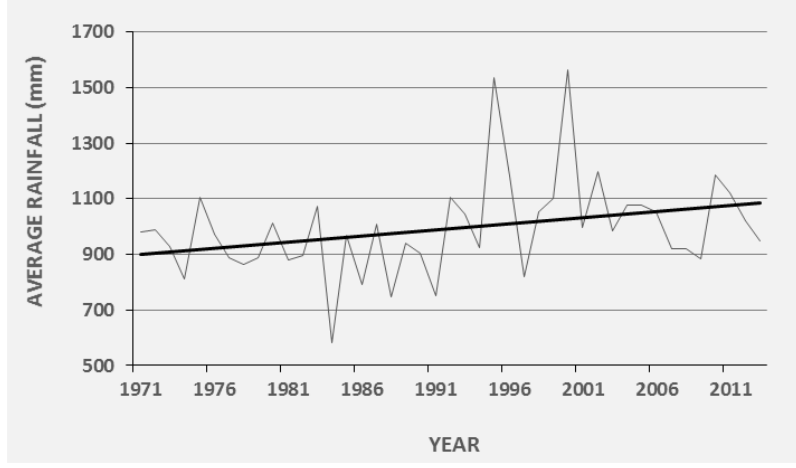

Figure 6. Mean annual rainfall total in Yelwa from 19712012

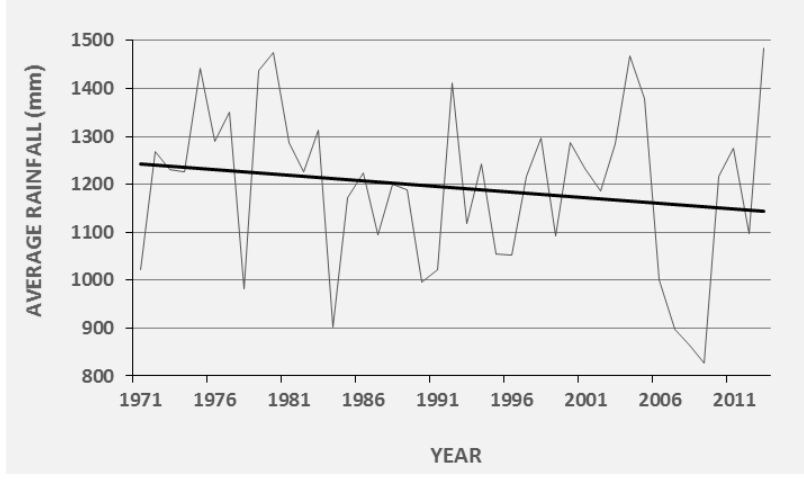

Figure 7. Mean annual Rainfall in Kaduna from 1971-2012 


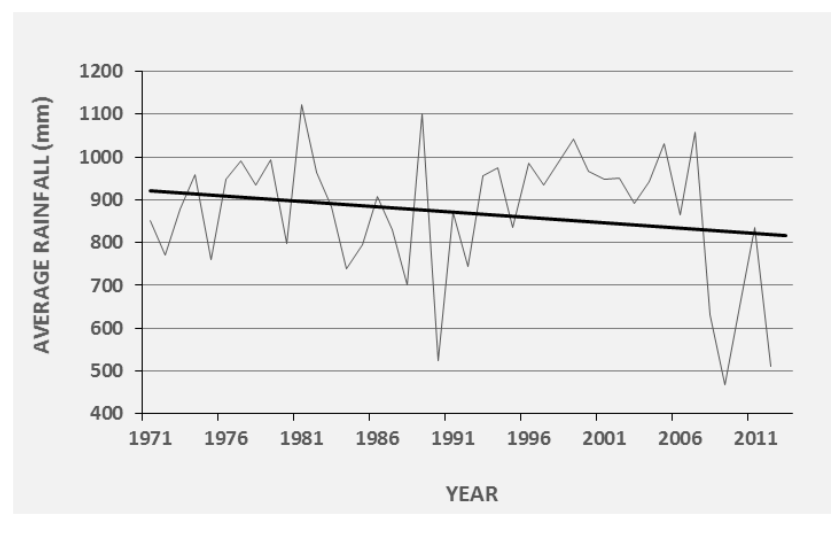

Figure 8. Mean annual rainfall total in Yola from 1971-2012

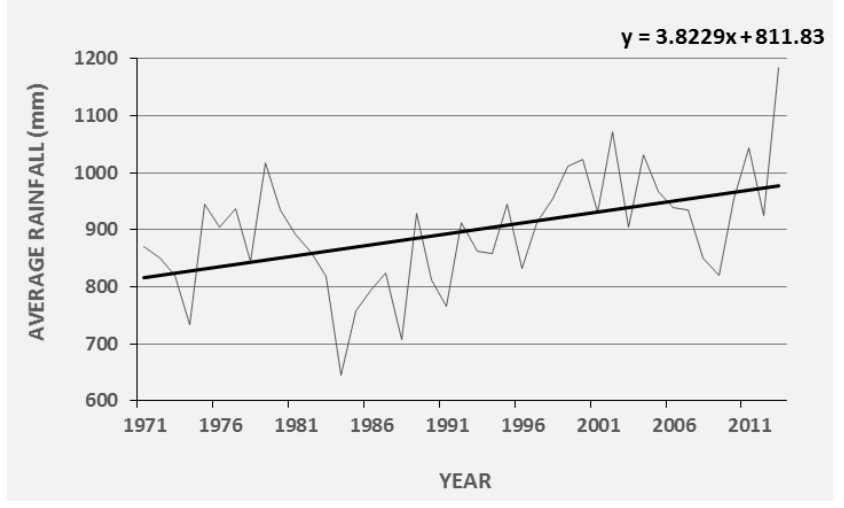

Figure 9. Mean annual rainfall total in the study area from 1971-2012

\subsubsection{Mean annual rainfall forcast from 2013 to 2030}

The forecasted linear equation of the time series was obtained as $y=205.25 x-412170$. The trend line shows a continuous rise from 2013 to 2030 (figure 10). This was an evidence that there will be an improved rainfall amount across the study area for the forecasted years.

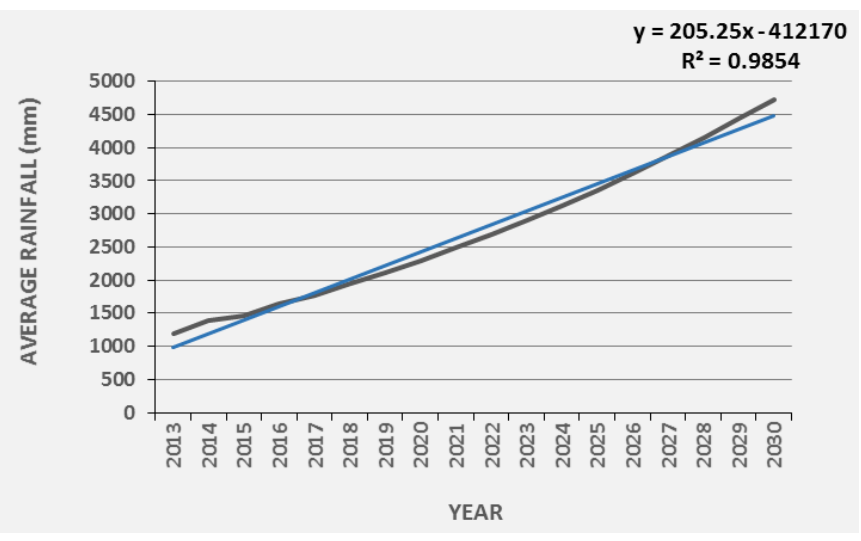

Figure 10. Mean annual rainfall in the study areas from 2013-2030 (forecast)

\section{CONCLUSIONS}

This study provides valuable insight into various degrees of rainfall as well as variability over the study area. The results revealed that Nguru recorded the least mean annual rainfall over the years, while the highest mean annual rainfall was recorded in Jos, it also has the minimum value of $12 \%$ of coefficient of variation. Kano has the highest rainfall variation of $38 \%$, followed by Nguru and Katsina with $30 \%$ each respectively. However, rainfall (both the observed and predicted) shows an increase within the study area. Further studies should be carried out using rainfall and temperature base on climatic zones of the northern region.

\section{REFERENCES}

[1] Oladipo EO. (1987). Some features of growing season precipitation fluctuations in the interior plains of North America. Journal of Climatology 7: 531-540.

[2] Hyuwa GN. (2005). Statistical Analysis of Daily Rainfall Characteristics at Jos (1930-2003). B.Sc. Dissertation, Department of Geography. Ahm.adu Bello University, Zaria.

[3] Kipkorir EC. (2002). Analysis of rainfall climate on the njemps flats, baringo district, Kenya. Journal of Arid Environments 50(3): 445-458. http//doi.org/10.1006/jare.2001.0917

[4] Herath S, Ratnayake U. (2004). Monitoring rainfall trends to predict adverse impacts - a case study from Sri Lanka (1964-1993). Global Environmental Change 14: 71-79.

[5] Ayoade JO. (1973). Annual rainfall trends and periodicities in Nigeria. Nigerian Geographical Journal 16: $167-172$.

[6] Ati OF. (1996). A comparison of methods to detect the onset of growing season and its trends for some stations in the sudan savanna in Northern Nigeria. M.Sc, Thesis, Department of Geography, Ahmadu Bello University, Zaria. http//doi/abs/10.1002/joc.712

[7] Hulme M, Osborn TJ, Johns TC. (1998) Precipitation sensitivity to global warming: Comparison of observations with HADCM2 simulations. Geophysical Re-search Letters 25: 3379-3382. http//doi.org/10.1029/98GL02562

[8] Kayano MT, Sansígolo C. (2008). Interannual to decadal variations of precipitation and daily maximum and daily minimum temperatures in southern Brazil. Theoretical and Applied Climatology 97: 81-90.

[9] Oguntunde PG, Abiodun BJ, Gunnar L. (2012). Spatial and temporal temperature trends in Nigeria, 1901-2000. Meteorology and Atmospheric Physics 118:95-105. $\mathrm{http} /$ doi.org/10.1007/s00703-012-0199-3

[10] Oladipo EO. (1993). Is the climate of Northern Nigeria becoming more arid. Paper Presented at the 36th Annual Conference of the Nigerian Geographical Association, Federal University of Technology Minna, pp. 13.

[11] Ati OF, Stigter CJ, Oladipo EO. (2002). A comparison of methods to determine the onset of the growing season in northern Nigeria. Int. J. Climatol. 22: 731-742.

[12] Adefolalu DO. (1986). Rainfall trends in Nigeria. Theoretical and Applied Climatology 37: 205-219. http//doi.org/10.1007/BF00867578

[13] Eludoyin (2009). Monthly variation in the 1985-1994 and 1995-2004 rainfall distribution over five selected synoptic stations in western Nigeria. Journal of Meteorology and Climate Science 7: 11-22. 